\title{
Evaluate the validity of the empirical correlations of clearance and friction coefficients to improve a scroll expander semi-empirical model
}

\author{
Cagri Kutlu ${ }^{1}$, Mehmet T. Erdinc ${ }^{2}$, Jing $\mathrm{Li}^{3}$, Yuehong $\mathrm{Su}^{1 *}$, Gang $\mathrm{Pei}^{4}$, Guangtao $\mathrm{Gao}^{4}$, Saffa \\ Riffat $^{1}$ \\ ${ }^{I}$ Department of Architecture and Built Environment, Faculty of Engineering, University of Nottingham, \\ Nottingham, NG7 2RD, UK \\ ${ }^{2}$ Department of Mechanical Engineering, Tarsus University, 33400, Mersin, Turkey \\ ${ }^{3}$ School of Engineering and Computer Science, University of Hull, Hull, HU6 7RX, UK \\ ${ }^{4}$ Department of Thermal Science and Energy Engineering, University of Science and Technology of China, 96 \\ Jinzhai Road, Hefei, 230027, China
}

This study presents a scroll expander modelling methodology for small scale power generation systems by combining scroll geometry and semi-empirical model. Although the semi-empirical model is quite popular, its dependence on several experimentally-determined scroll geometrical and operational parameters makes this approach inflexible for different capacities and operating conditions. Some studies have sought to improve its flexibility in terms of using different working fluids and more accurate empirical parameters, however, those improved models still depend on a considerable number of experimentally-obtained scroll parameters. Therefore, in this study, a practical methodology for a simpler semiempirical model combined with the operational flexibility of the scroll geometry is presented. Firstly, the flow rates of mainstream and leakage flows are analysed, where a correlation between scroll clearance and pressure ratio is determined. Secondly, a simpler approach to the semi-empirical model of scroll expander is proposed, whereby dependent parameters have been reduced to two parameters by using scroll geometrical calculations. The model is further improved to predict the rotational speed and electricity output by considering the overall friction coefficient of the coupled expander-generator unit. The findings are then compared with the results of an experimental study. The results show that the effective clearance values between scrolls vary according to pressure ratios, increasing from $20 \mu \mathrm{m}$ to $34 \mu \mathrm{m}$. Mass flow rate can be predicted within $10 \%$ deviation from the experimental results for the same inlet conditions and rotational speed at a transient state. Additionally, considering steady state conditions, modelling results show that the rotational speed and electricity output can also be predicted within $8 \%$ and $7.5 \%$ of deviation, respectively.

Keywords: Clearance, Empirical correlation, Leakage area, Friction coefficient, Scroll geometry, Semi-empirical model

* Corresponding author. Yuehong Su, yuehong.su@ nottingham.ac.uk 


\section{Introduction}

Heat recovery usage and renewable solutions for power generation have increased dramatically in the past few decades. The organic Rankine cycle (ORC) system is the most widely examined option among the low temperature power generation solutions. Its main advantage is the simplicity and availability of its components. In this kind of systems, an organic fluid is used as a working fluid which is better adapted than water to low temperature heat sources [1]. ORC systems can therefore be used effectively in low temperature heat sources, especially for small scale applications. They are suitable for various low temperature applications such as solar heat, geothermal energy and waste heat recovery. Given the nature of these heat sources, the useful heat fluctuates during operation, so the ORC system components must adapt to its operating regime to ensure optimal system operation [2]. Alternatively, components may be operated in off-design conditions with a considerable performance reduction.

The key component of the ORC system is the expansion device which produces work in expense of pressure reduction. The isentropic efficiency and mass flow rate of an expansion device are key factors in the overall performance of ORC system. For small-scale systems, an efficient and cost effective expansion device must be chosen. It is known that scroll machines produce low noise, little vibration and are of high efficiency, therefore scroll compressors have been used for years in many applications. Therefore, scroll expanders are quite popular choice for small-scale ORC applications. Moreover, tolerance of the off-design operation makes this type of expander the best option for fluctuating heat source applications such as solar ORC systems [3], to provide heat and power generation [4] or power generation with cooling in buildings [5].

In order to simulate scroll expanders, three types of modelling have been presented and discussed in a review paper prepared by Song et al. [6]. They state that empirical and semiempirical models are more stable and time-saving in computations, while a geometric model can reflect the dynamic behaviour of a scroll expander during the whole working process; however, the geometric model is more time-consuming in computation. Dickens et al.[2] compared three different modelling methods of ORC in their experimentally validated study, namely, a constant efficiency method, a polynomial-based method and a semi-empirical method. They presented that semi-empirical models are the most reliable for off-design operation of the ORC. The expander semi-empirical model was proposed by Lemort et al. [7] and has more recently been the most preferable model as it describes the most influential component in an ORC system. In this model, several stages are included in the whole thermodynamic process. It offers a satisfactory simulation speed, modelling accuracy and extrapolation capabilities [8]. In their study, the model results were compared with the experimental results with an open-drive scroll expander. The maximum deviation was found to be 5\%, which means that this model has a very good accuracy [6]. Moreover, this semiempirical model can be adapted to screw expanders [9], [10], reciprocating piston expanders [11] and a roots expander [12] by using the same formulations.

Although this semi-empirical model is quite popular, its dependence on several experimentally-determined expander geometrical and operational parameters under a certain condition make this approach inflexible for different capacities and operating conditions of scroll expander in ORC systems. Some papers have investigated how to improve the model 
by upgrading parameters. Giuffrida [13] looked at improving the flexibility of the model for use with a wider range of working fluids. He suggested an approach of modifying the heat transfer coefficients by including the physical properties of a working fluid [7], while other parameters remain the same because they are not dependent on the physical properties of a working fluid. Lemort et al. [14] experimentally showed that the effective leakage area can vary according to inlet pressure and thus presented another empirical equation for the area calculation under different conditions. Similarly, Mendoza et al. [15] presented an empirical equation for leakage area for ammonia as a working fluid. Giuffrida [16] used a load dependent leakage area equation and Ziviani et al. [17] proposed a modification of the leakage area using some constant values, pressure difference and rotational speed, however, parameters would still need to be determined via an experiment.

Gao et al. [18] experimentally tested two scroll expanders with different displacement volumes. They reported that the isentropic efficiencies of the two expanders were different even under the same operating conditions. When a different capacity or brand of expander is used, the researchers would have to test their own machine and determine the machine's parameters first before they can build a model for parametric studies. Twomey et al.[19] successfully adopted such approach to simulate a solar ORC system. Ayachi et al.[20] developed and characterized a semi-empirical model for high pressure operations using R245fa. Miao et al. [21] enhanced its expander model by scroll geometry and defined a leakage area and other parameters from the experiment. Recently, Muye et al.[22] characterized and modelled the scroll expander using R134a refrigerant as a working fluid.

As described above, many studies have tried to improve the semi-empirical modelling or adapt this approach to different scroll expanders, however, those modelling studies always chose a rotational speed to predict the shaft power. But, the rotational speed of a scroll expander should be synchronized with the torque balance of the coupled expander-generator unit rather than being chosen. Therefore, this study aims to advance the semi-empirical model to predict the rotational speed and electricity output of the coupled expander-generator unit. The main objective of the study is to reduce the number of dependent parameters of the semiempirical model to two empirical parameters by using scroll geometry.

The proposed methodology is outlined in the following sections in two parts. Firstly, flow rates of mainstream and leakage flows are considered, given that leakage flow is responsible for lower volumetric efficiency and has an influence on expander performance. Evaluation of the validity of the empirical clearance model is conducted to predict flow rates. Leakage area of the scroll is calculated by scroll geometrical methodology, in which clearance between the scrolls are discussed and determined by experimental analysis to draw a conclusion. Secondly, the semi-empirical model is adapted to predict the rotational speed of a scroll expander by coupling with an electromechanical model. An experimental data fitting is used to determine two key parameters of the electromechanical model. By applying these models, electricity output can be predicted.

\section{Methodology}

The semi-empirical model is the most preferred scroll expander model with good accuracy. The model consists of several hypothetical stages to explain the working principle of the 
scroll expander. A schematic of the model with all stages is shown in Fig. 1 and equations can be found from the related reference. Subscript $s u$ indicates supply conditions which define expander inlet pressure and temperature. From state $s u$ to $s u, 1$, the working fluid is assumed to have a pressure drop adiabatically and then reject heat to the expander shell, reaching state $s u, 2$. From this point, leakage flow leaves from the mainstream and the rest of the working fluid is expanded according to the built-in volumetric ratio of expander, followed by a pressure change at constant volume to count under or over-expansion. Afterwards, the mainstream working fluid is mixed with leakage flow and finally exhaust heat transfer happens. Subscripts in, leak, ad and ex indicate internal, leakage, adapted and exhaust, respectively.

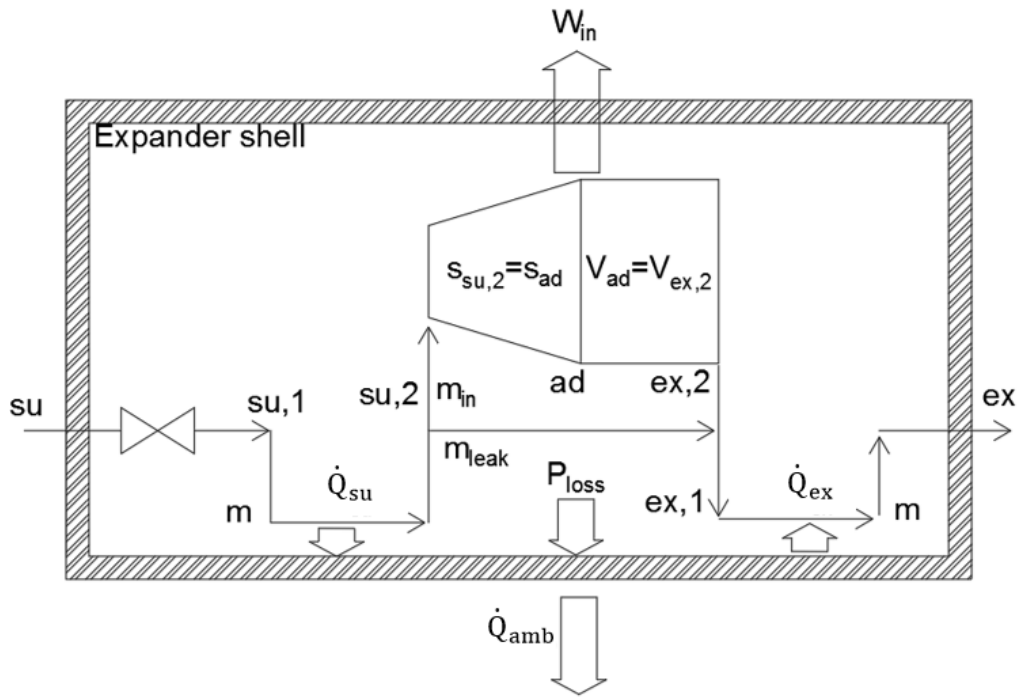

Fig. 1. Semi-empirical model for an open-drive scroll expander by Lemort et al.[7]

For the semi-empirical model, nine parameters as listed in Table 1 are required. In the study by Lemort et al. [7], these parameters were determined and validated by an experimental work. These parameters are therefore valid only for the specific tested expander, meaning that researchers cannot flexibly use this for different expander capacities. Obviously, dependency on empirically-determined parameters makes this model limited. By using a scroll geometry, some of these parameters can be calculated and used in the semi-empirical model, thus, creating a more general model.

Table 1. Required parameters for the semi-empirical modelling [7]

\begin{tabular}{|c|c|c|}
\hline No & Dependency & Parameter \\
\hline $\mathbf{1}$ & Geometry & Swept volume, $\left(V_{s w}\right)$ \\
\hline $\mathbf{2}$ & Geometry & Built-in volumetric ratio, $(\mathrm{BVR})$ \\
\hline $\mathbf{3}$ & Geometry, Operating condition & Leakage area, $\left(A_{\text {leak }}\right)$ \\
\hline $\mathbf{4}$ & Geometry & Supply port cross sectional area, $\left(A_{s u}\right)$ \\
\hline $\mathbf{5}$ & Geometry, Operating condition & Nominal mass flow rate, $\left(\dot{m}_{n}\right)$ \\
\hline $\mathbf{6}$ & Geometry, Operating condition & $\begin{array}{c}\text { Heat transfer coefficient and related area for the } \\
\text { outside of the shell, }\left(A U_{a m b}\right)\end{array}$ \\
\hline $\mathbf{7}$ & Geometry, Operating condition & $\begin{array}{c}\text { Heat transfer coefficient and related area for the } \\
\text { supply stage, }\left(A U_{s u, n}\right)\end{array}$ \\
\hline $\mathbf{8}$ & Geometry, Operating condition & $\begin{array}{c}\text { Heat transfer coefficient and related area for the } \\
\text { exhaust stage, }\left(A U_{e x, n}\right)\end{array}$ \\
\hline
\end{tabular}




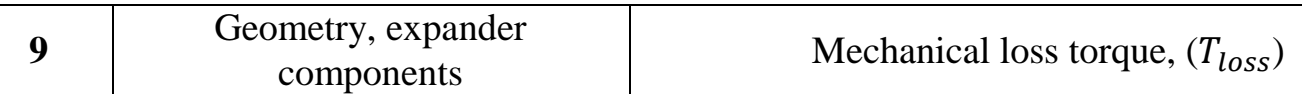

Our proposed approach aims to avoid the dependency on empirically-determined geometric parameters, but to use scroll geometry equations instead to empirically determine them, so that the semi-empirical model can be more flexible for design and modelling applications. Calculations of leakage area, heat transfer area, heat transfer coefficients, etc. using geometric parameters and operating conditions are given in following sections.

\section{Calculation of leakage area from scroll geometry}

Scroll geometry is one of the main factors affecting the scroll compressor and expander performances. A reliable and simplified model is necessary to merge with a thermodynamic model. Compared to scroll expanders, studies on scroll compressors are more prolific and provide significant knowledge which can be applied to the design of the scroll expanders [23]. The scroll geometry consists of equations to identify scroll profiles and calculates volumes of the chambers and leakage areas according to the orbiting angle. To build an accurate and flexible mathematical model, some of the geometric features need to be determined.

\subsection{Scroll geometry equations}

The shape of the scroll is an involute of circle and a scroll is defined by two involutes, namely, an inner and outer involute. These profiles are established according to a differential equation given in Eq. (1) [23].

$$
\frac{\delta L(\phi)}{\delta \phi}=r_{b}
$$

where $L$ indicates tangential distance, $\phi$ represents involute angle, and $r_{b}$ is the base circle radius. For inner and outer involutes equations are given as:

$$
\begin{aligned}
& L_{i}=r_{b}\left(\phi-\phi_{i 0}\right) \\
& L_{o}=r_{b}\left(\phi-\phi_{o 0}\right)
\end{aligned}
$$

The thickness of the scroll is determined by:

$$
t_{s}=L_{o}-L_{i}=r_{b}\left(\phi_{i 0}-\phi_{o 0}\right)
$$

By fixing the origin of the coordinate system at the centre of the base circle, the individual coordinate points $x$ and $y$ on the involute can be determined by Eq. (5) and Eq. (6)[24].

$$
\begin{aligned}
& x=r_{b}\left(\cos \phi+\left(\phi-\phi_{0}\right) \sin \phi\right) \\
& y=r_{b}\left(\sin \phi-\left(\phi-\phi_{0}\right) \cos \phi\right)
\end{aligned}
$$

Another important geometric feature is ending angle $\phi_{e}$. The ending angle is generally the same for both inner and outer involutes. When the base circle radius, initial and ending angle are determined, it is possible to form a scroll by using the given equations.

The fixed scroll works with another scroll known as the moving or orbiting scroll, which are assembled together in scroll machines. These two scrolls are in conjugacy; the orbiting scroll 
is then offset by a fixed amount away from the base circle centre of the fixed one. The orbiting scroll orbits (not rotates) around the centre point of the base circle of the fixed scroll. There is a conjugacy between the fixed and orbiting scrolls, which means the two scrolls make contact with each other perfectly at certain conjugate angles. The orbiting radius can be calculated by Eq. (7):

$$
r_{o r}=r_{b} \pi-t_{s}=r_{b}\left(\pi-\phi_{i 0}+\phi_{o 0}\right)
$$

Other relevant parameters, also given in equations, such as pitch and ending angle are provided by Ma et al.[25].

$$
\begin{gathered}
P i t=2 \pi r_{b} \\
\phi_{e}=\left(2 N_{c}+1 / 2\right) \pi
\end{gathered}
$$

All other specifications about scroll geometry can be found in the paper written by Bell et al. [26].

\subsection{Leakages}

Normally, the fixed scroll and orbiting scroll should mesh perfectly during the operation to obtain higher volumetric efficiency and performance, however, internal leakages can occur inside the expander. It has been reported that there are two kinds of leakages in scroll machines, namely, flank leakage and radial leakage. Flank leakage appears through the clearance between the side surfaces of fixed and orbiting scrolls. Radial leakage occurs through the clearance between the tip wall and base plate of the scrolls. These two kinds of leakages are schematically shown in Figure 2.

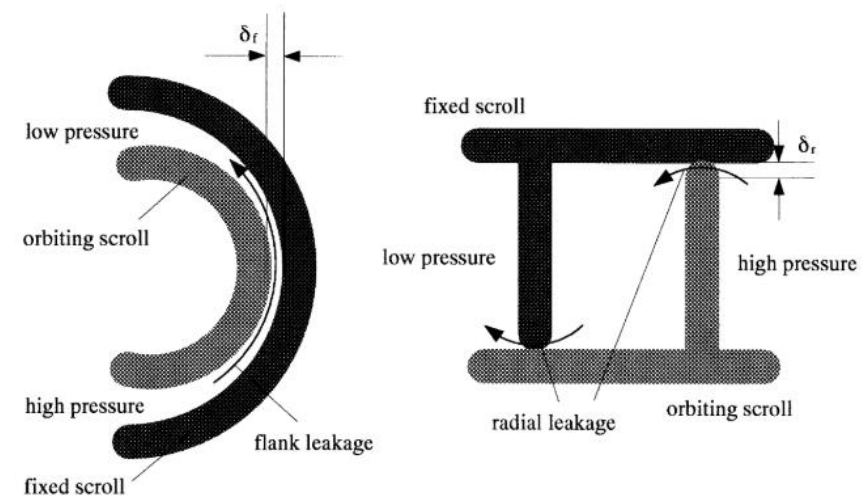

Fig. 2. Two kinds of leakages in a scroll expander [27]

Different clearance values have been used by several studies to calculate the leakage area. Some studies have used variable clearance according to operation pressure, some have used a constant value for flank and another constant for radial clearance, however, some authors have preferred to use fixed values for both clearances. A summary of clearance values is given in Table 2. $\delta_{r}$ and $\delta_{f}$ indicate radial and flank clearances, respectively. Ma et al. [25] and $\mathrm{Wu}$ et al. [28] used convenient equations for the calculation of the leakage areas. As flank leakage occurs on both sizes, the length of the gap is the scroll height; the total flank leakage area is therefore: 


$$
A_{\text {flank }}(\theta)=2 h_{s} \delta_{f}
$$

For the radial leakage, the area changes with the orbiting angle as the chambers are enlarging and shrinking during operation.

$$
A_{\text {radial }}(\theta)=\delta_{r} 2 \pi r_{b}(2(i-1) \pi+\theta)
$$

As seen from the equation, the radial leakage area depends on the orbiting angle. To find the overall effective leakage area $A_{\text {leak }}$ of a whole scroll, an angularly maximum radial leakage value is added to the flank leakage area.

Table 2. Clearance values for scroll machines

\begin{tabular}{|c|c|c|c|}
\hline Reference & Information & $\boldsymbol{\delta}_{\boldsymbol{r}}$ & $\boldsymbol{\delta}_{\boldsymbol{f}}$ \\
\hline$[27]$ & Scroll compressor & $1.1 \cdot 10^{-6}\left(\frac{P_{\text {dis }}}{P_{\text {suc }}}-1.67\right)+10^{-6}$ & $-9.615 \cdot 10^{-5}\left(\frac{P_{\text {dis }}}{P_{\text {suc }}}-1.67\right)+20 \cdot 10^{-6}$ \\
\hline$[29]$ & Scroll compressor & {$\left[0.85 \cdot\left(\frac{P_{\text {dis }}-P_{\text {back }}}{P_{\text {suc }}}\right)+1.65\right] \cdot 10^{-6}$} & {$\left[-6.11 \cdot\left(\frac{P_{\text {dis }}-P_{\text {back }}}{P_{\text {suc }}}\right)+32\right] \cdot 10^{-6}$} \\
\hline$[30]$ & $\begin{array}{c}\text { Vapor injection scroll } \\
\text { compressor }\end{array}$ & $1.1 \cdot 10^{-6}\left(\frac{P_{\text {dis }}}{P_{\text {suc }}}-1.67\right)+10^{-6}$ & $2.11 \cdot 10^{-6}\left(\frac{P_{\text {dis }}}{P_{\text {suc }}}-1.67\right)+20 \cdot 10^{-6}$ \\
\hline$[31]$ & Air scroll expander & $60 \mu m(5-100 \mu m)$ & $60 \mu m(5-100 \mu m)$ \\
\hline$[32]$ & Air scroll expander & $40 \mu m$ & $40 \mu m$ \\
\hline$[33]$ & ORC scroll expander & $40 \mu m$ & $40 \mu m$ \\
\hline$[28]$ & ORC scroll expander & $40 \mu m$ & $10 \mu m$ \\
\hline$[34]$ & Air scroll expander & $15 \mu m$ & $10 \mu m$ \\
\hline$[35]$ & Air scroll expander & $15 \mu m$ & $10 \mu m$ \\
\hline$[25]$ & Air scroll expander & $10 \mu m$ & \\
\hline
\end{tabular}

\section{Thermodynamic Model}

The thermodynamic model consists of mass flow rate calculation and energy conservation equations of the working fluid. Heat transfer to the ambient from the expander shell needs to be calculated and motion analysis need to be conducted to predict electricity output.

\subsection{Mass flow rate}

The semi-empirical model uses a given suction port area to calculate the mass flow rate using the adiabatic pressure drop approach. This study adopts a different approach considering the rotation of scroll, i.e., the expander intake chamber is filled with supplied working fluid and its volume changes with the orbiting angle; the cumulated mass in the chamber reaches the maximum at the end of one full rotation and all collected working fluid is then transferred into the first expansion chamber. During this operation, the pressure in the intake chamber remains same with the supply pressure. However, the used equations after this point are the same as those in the semi-empirical modelling approach.

The theoretical mass flow rate can be calculated by using inlet conditions and swept volume; however, leakage flow rates need to be included to find the total mass flow rate coming into the expander. The general mass flow rate equation is given in Eq. (12) [36]: 


$$
\dot{m}_{\text {total }}=\rho_{s u} V_{s w} \frac{N}{60}+\dot{m}_{\text {leak }}
$$

The leakage mass flow rate can be calculated by assuming it is the isentropic flow through a simple convergent nozzle of throat area as $A_{\text {leak }}$.

$$
\dot{m}_{\text {leak }}=\rho_{\text {leak }} A_{\text {leak }} \sqrt{2\left(h_{\text {su }}-h_{\text {leak }}\right)}
$$

To calculate leakage enthalpy and density, the pressure at the throat of nozzle is used. The throat pressure corresponds to the maximum value between critical pressure and exhaust pressure. The critical pressure in the throat is found assuming the vapor is ideal gas.

$$
P_{\text {crit }, \text { leak }}=P_{s u}\left(\frac{2}{\gamma+1}\right)^{\frac{\gamma}{\gamma-1}}
$$

$\gamma$ is the ratio of specific heat at constant pressure relative to that at constant volume. As indicated above, a clearance value needs to be determined experimentally to calculate $A_{\text {leak }}$ value for each operating condition. A flow chart of the calculation procedure is shown in Fig. 3 . The procedure is started with calculation of the theoretical mass flow rate $\left(\dot{m}_{t h}\right)$ by using the experimentally obtained rotational speed, inlet pressure and temperature. Leakage flow rate $\left(\dot{m}_{\text {leak }}\right)$ is found by subtracting the theoretical flow rate from the experimentally recorded total flow rate $\left(\dot{m}_{\text {total }}\right)$. Once $\dot{m}_{\text {leak }}$ is known, using leakage area $\left(A_{\text {leak }}\right)$ which can be found from scroll geometry as a function of the clearance, the empirical clearance equation is obtained.

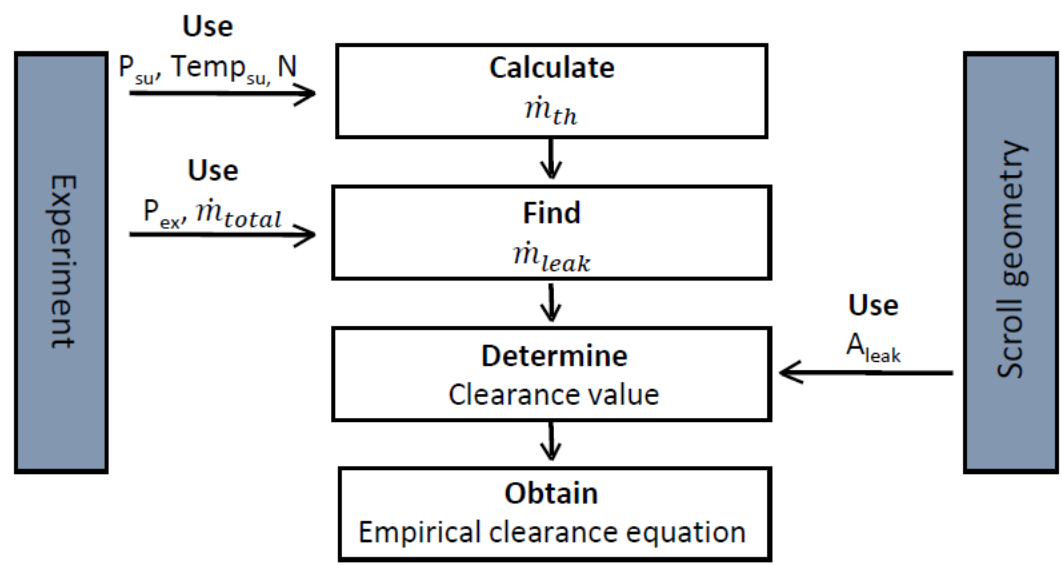

Fig. 3. Method to obtain an empirical equation of clearance

\subsection{Heat transfer equations}

During operation of the expander, heat is transferred from working fluid to the base plate and to other chambers by scrolls. To determine the heat transfer rate, firstly heat transfer coefficient of the working fluid needs to be found. Jang and Jeong [37] presented an empirical heat transfer equation for the heat transfer in a rectangular duct with a fixed heating wall and an oscillating wall. The equation is given in Eq. (15): 


$$
N u=\left(1+3.5 \frac{D_{h}}{D_{m}}\right)\left(1+8.8\left(1-e^{-5.35 S t}\right)\right) N u_{D B}
$$

where $D_{h}$ is hydraulic diameter of the flow duct, $D_{m}$ represents the mean diameter of the scroll curvature, a related equation is given in Eq. (16):

$$
D_{m}=2 r_{b}(2(i-1) \pi)
$$

$S t$ is Strouhal number, which is used for correcting the oscillating movement, can be given by:

$$
S t=\frac{f_{o} A_{\max }}{\bar{U}}
$$

where $f_{o}$ is oscillating frequency, $A_{\max }$ indicates oscillating amplitude, $\bar{U}$ is the mean velocity of the fluid, which are given by:

$$
\begin{gathered}
f_{o}=\frac{\omega}{2 \pi} \\
A_{\text {max }}=r_{o r} \\
\bar{U}=\frac{\dot{m}_{\text {total }}}{r_{o} h_{s} \rho}
\end{gathered}
$$

The mean hydraulic diameter is calculated from Eq. (21):

$$
D_{h}=\frac{2 r_{o r} h_{s}}{r_{o r}+h_{s}}
$$

Dittus-Boelter convection heat transfer correlation can be used for $N u_{D B}$.

$$
N u_{D B}=0.023 \operatorname{Re}^{0.8} \operatorname{Pr}^{1 / 3}
$$

The heat transfer area between the chamber and base plate is:

$$
A_{p(i)}=\frac{2 V_{c(i)}}{h_{s}}
$$

For the last chamber:

$$
A_{(i)}=2 \pi R_{s h} h_{s}
$$


$R_{s h}$ is shell radius and its equation is given in Eq.(26) [25]:

$$
R_{s h}=\sqrt{\left(r_{b}\left(\phi_{e}+\phi_{0}\right)+r_{o r}\right)^{2}+r_{b}{ }^{2}}
$$

\section{Motion equations}

Rotational speed is an independent parameter in the base semi-empirical approach but its effect on flow rate, leakages and friction losses cannot be ignored. Pressure difference between chambers in the expander generates forces in different directions such as tangential, axial and radial. Of these forces, tangential force drives the rotation of the orbiting scroll. Every point on the orbiting scroll rotates along a circle with the same diameter but with a different circular centre and a torque is generated. This torque called tangential torque $T_{t}$. This torque drives the rotation, but counter torques must be eliminated. Mechanical friction torque $T_{f r}$ and electromechanical torque $T_{e m}$ generate counter torque against rotation. The expander-generator rotation torque balance is given in Eq. (26) [38]:

$$
\left(J_{o r}+J_{\text {sha }}+J_{a}+J_{o l d} \sin ^{2} \theta\right) \frac{d \omega}{d t}-J_{o r} \sin \theta \cos \theta \omega^{2}=T_{t}-T_{f r}-T_{e m}
$$

where $J$ represents the inertia moment of the rotating parts, subscripts or, a, sha and old are for orbiting scroll, armature, shaft and Oldham ring, respectively.

Friction torque is not easy to define as the expander comprises many parts. Ma et al. [25] recommended Eq. (27) for summing the frictions in the expander and generator.

$$
T_{f r}=f_{s g} \omega
$$

where $f_{s g}$ is the overall dynamic friction coefficient and needs to be determined by fitting the experimental data.

Regarding the electromechanical torque, Eq. (28) can be used [39]:

$$
T_{e m}=K_{t} I_{a}
$$

where $I_{a}$ and $K_{t}$ are current and torque constant, respectively. Generated current and angular speed are correlated in Eq. (29) [39]:

$$
K_{e} \omega=\left(R_{a}+R_{\text {load }}\right) I_{a}+L_{a} \frac{d I_{a}}{d t}
$$

where $K_{e}$ is back electromotive force constant and its value is taken as $0.12 \mathrm{NmA}^{-1} . R_{a}$ and $R_{\text {load }}$ are resistances and $L_{a}$ is armature inductance.

To obtain empirical equations for the overall dynamic friction coefficient and generator specifications, a flow chart in Fig 4 is given. In order to find torque balance for steady state operation, $T_{e m}, T_{f r}$ and $T_{t}$ are required. $T_{e m}$ is calculated with utilizing experimentally measured values, namely $I, V$ and $N . P_{\text {shaft }}$ is calculated from semi-empirical model [7] by using $P_{s u}, T e m p_{s u}, P_{e x}$ and $N$ from the experimental data and heat transfer areas that are calculated from the scroll geometry correlations for given scroll geometry parameters. Then, 
$P_{\text {shaft }}$ is converted to the torque by using rotational speed and $T_{t}$ is found. After applying balance equation, $T_{f r}$ is found. This procedure is repeated for all experimental data then overall dynamical friction coefficient correlation is obtained.

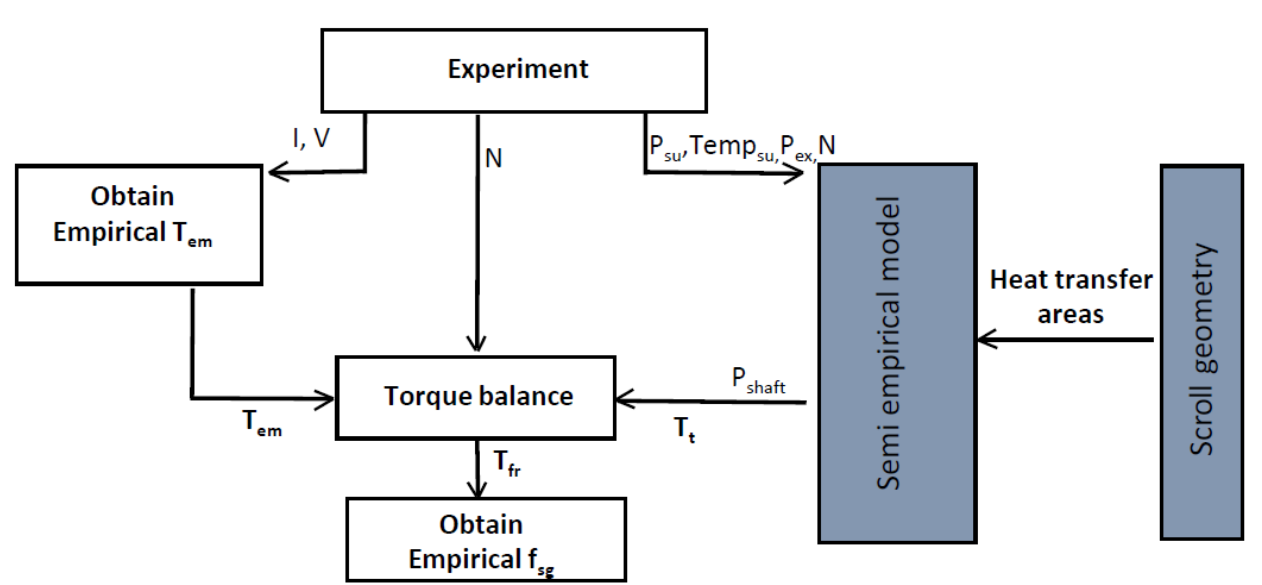

Fig. 4. A procedure to obtain empirical friction coefficient.

\section{Results and discussion}

\subsection{Experimental rig and expander model implementations}

In order to validate the proposed model with an experiment, the same experiment setup has been used as presented in another study by Li et al.[40]. A test rig was set in the University of Science and Technology of China. In this experimental setup, an ORC unit was tested using an oil free semi hermetic scroll expander produced by Air Squared, Inc. [41]. Fig. 5 shows a diagram of the ORC system. The system has three loops. First, the oil cycle; the oil is heated to the desired temperature by the controller then heat is transferred into working fluid by the evaporator. Second, ORC cycle; R123 is used as a working fluid which is evaporated via an evaporator by transferred heat from the oil. Working fluid enters the scroll expander and drives it to rotate. The generator is magnetically connected to the expander's rotating shaft and generates electricity. Thereafter, the condenser rejects heat from the R123 refrigerant and changes its state to liquid. The final cycle is the cooling water cycle; cooling water absorbs heat from the working fluid at the condenser. This heat is then carried away to a cooling tower. 


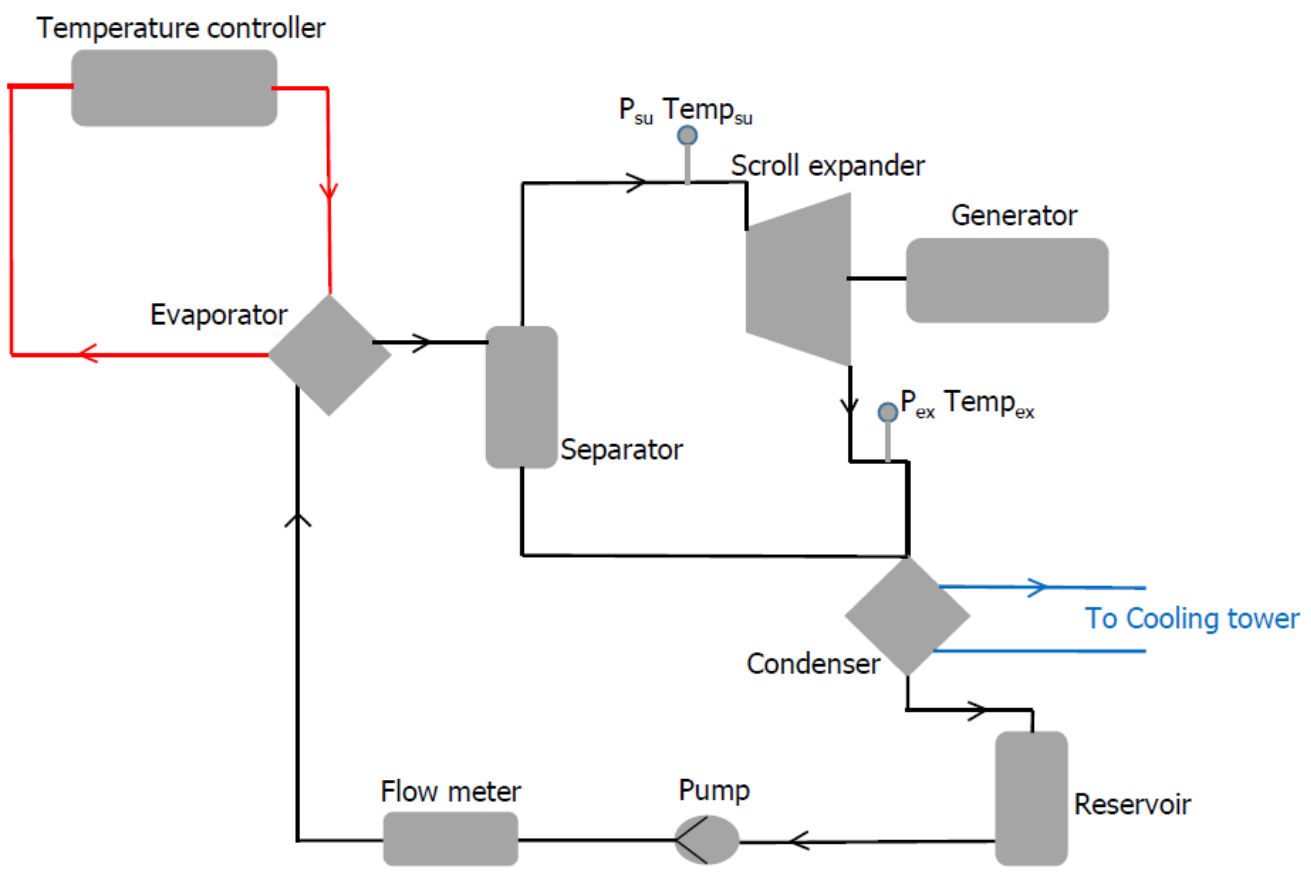

Fig. 5. Diagram of the ORC system

The measured parameters include temperature and pressure, denoted by $\mathrm{T}$ and $\mathrm{P}$ next to the lines. R123 mass flow rate and electricity output were measured by the flow meter and digital power meter, respectively. In order to give accurate and reliable results, evaluation of the uncertainties of the experimental setup is very important. Copper-constantan thermocouples are used for measuring the temperatures with an accuracy of $\pm 0.5{ }^{\circ} \mathrm{C}$. To measure pressure, three types of ceramic pressure transmitters produced by Huba Control Co. were utilized. The pressure ranges were -1 to 9 bar (scroll expander outlet, condenser outlet and organic fluid pump outlet), 0-25 bar (scroll expander inlet) and 0-30 bar (organic fluid pump inlet and evaporator outlet). Their accuracies were $\pm 1.0 \%$. The R123 mass flow rate was measured by the flow meter (MFM2081K-60P/DN25) fabricated by KROHNE Group. The zero-point stability was $\pm 0.012 \mathrm{~kg} / \mathrm{min}$, and accuracy was $\pm 0.15 \% \mathrm{MV}+\mathrm{Cz}$. The output voltage, current, electricity and frequency of the generator were measured by the digital power meter (8716C1T-RS) provided by Qingdao Qingzhi Company, and the accuracies were $\pm 0.5 \%$, $\pm 0.5 \%, \pm 0.5 \%$, and $\pm 0.1 \%$, respectively, given in the reference [40]. An uncertainty analysis has been conducted according to the method by Holman [42], and it is found that the uncertainty in the obtained power is $\pm 0.7 \%$.

The oil-free scroll expander E15H022A-A03 has been used for tests. The expander's maximum output power, speed, inlet temperature and pressure are $1 \mathrm{~kW}, 3600 \mathrm{rpm}, 175{ }^{\circ} \mathrm{C}$ and 13.8 bar, respectively. The coupled generator (AB30L) is a single-phase generator produced by Wanco, Inc. It is connected to the expander via a magnetic coupler in the housing. The rated volts, amps, hertz and speed are $240 \mathrm{~V}, 10 \mathrm{~A}, 50$ and $3000 \mathrm{rpm}$.

According to datasheet of the expander given by the company, the built-in volume ratio is 3.5 and displacement volume is $14.5 \mathrm{~cm}^{3}$, which can be also calculated from the scroll geometry. Thankfully, Ma et al. [25] used the same expander in their work, measuring and presenting the geometric parameters of the scrolls. Thus, by using the given scroll geometry parameters, 
Table 3. Geometric parameters of the tested scroll expander [25]

\begin{tabular}{|l|c|c|}
\hline \multicolumn{1}{|c|}{ Parameter } & Symbol & Value \\
\hline Height of scroll & $h_{s}$ & $22.4 \mathrm{~mm}$ \\
\hline Radius of the base circle & $r_{b}$ & $2.37 \mathrm{~mm}$ \\
\hline Thickness of the scroll & $t_{s}$ & $4.08 \mathrm{~mm}$ \\
\hline Number of chambers & $\mathrm{Nc}$ & 4 \\
\hline Pitch of the scroll blade & $P i t$ & $14.91 \mathrm{~mm}$ \\
\hline $\begin{array}{l}\text { Start angle of the } \\
\text { involute }\end{array}$ & $\phi_{0}$ & $49.25^{\circ}$ \\
\hline Swept volume & $V_{S W}$ & $14.5 \mathrm{~cm}^{3}$ \\
\hline Built-in volume ratio & $B V R$ & 3.5 \\
\hline
\end{tabular}

By using given parameters, the scroll profile has been formed and scroll positions of given orbiting angles are given in Fig. 6. 

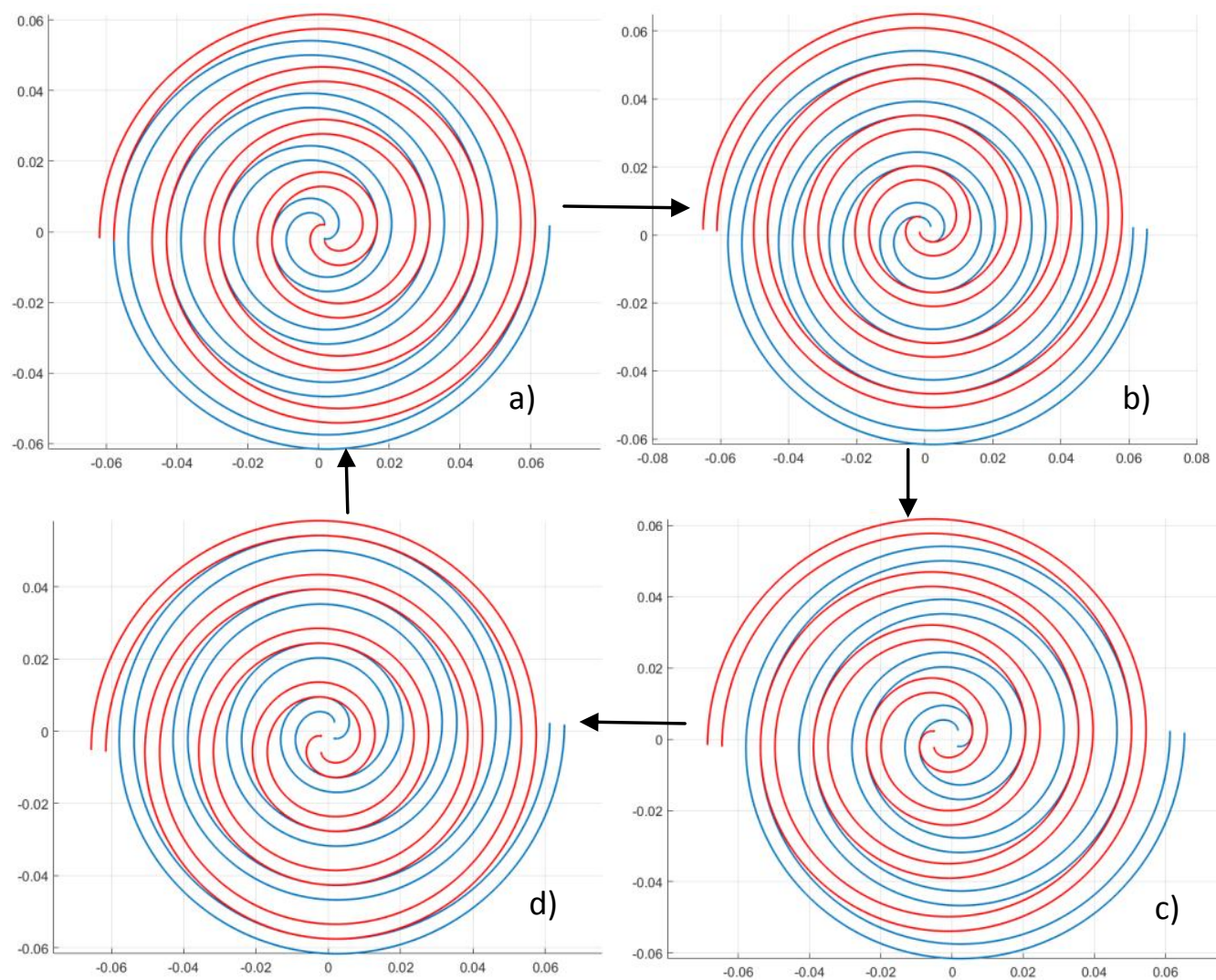

Fig. 6. Scroll position for orbiting angle: a) $\theta=0$, b) $\theta=\pi / 2$, c) $\theta=\pi$, d) $\theta=3 \pi / 2$

The inlet and outlet pressures, rotational speed and inlet and outlet temperatures of the expander from the experiment have been used for the analysis. Fig. 7 shows experimental data. In this experiment, pump frequency has been increased gradually so that inlet pressure is increased, however, temperatures and pressure outlet are changed slightly. Time step was 5 seconds, thus, the system can be considered as in transient state. By using experimental data, the effective clearance value of the scroll is determined first. Later, the effect of the pressure ratio on rotational speed and efficiencies are discussed. 


\subsection{Scroll clearance}

In order to find leakage area, Eqs. (10)-(11) can be used but these equations require clearance values between the scrolls. As seen from Table 2, there is no agreement about the clearances among different studies. For the scroll compressors, the manufacturer gave some equations to calculate them, however, it is not possible to use the same equations for the expander applications because the given expander operates oil free and reverse operation makes a decrease in the sealing effectiveness likely, hence, the authors used higher clearance values for the expanders. In order to determine the real clearance value, experimental data have been used for solving Eqs. (12)-(14) but the leakage area must be determined first. By using the geometrical parameters given in Table 3 of the Air Squared expander's leakage areas have been calculated.

Larger clearances result in larger leakage areas. By using the area equation with experimental mass flow rates, real clearance can be determined. Fig. 8 shows clearance variation based on experimental mass flow rate. Data from three set of experiments' data have been used and effect of pressure ratio on clearance value is obtained. Clearance starts around $20 \mu \mathrm{m}$ and increases with the pressure ratio. Increment of the clearance by pressure ratio looks reasonable as scroll pairs consist of one fixed and one orbiting scroll and it is possible to have a larger effective gap at higher pressure ratio. The fitted curve is a logarithmic function given in Eq. (30) which reaches $34.85 \mu \mathrm{m}$ towards infinitely large pressure ratio. It is also reasonable to have a maximum value given that scrolls are rigid materials and also rotation is restricted by friction, therefore an effective gap increment is limited. 


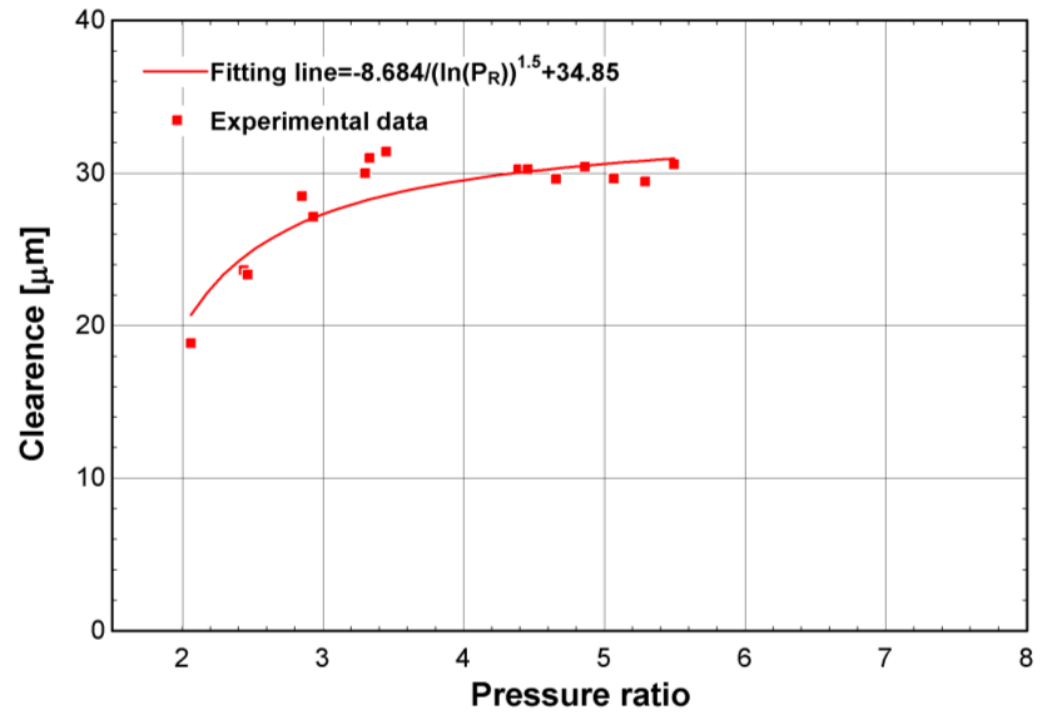

Fig.8. Scroll clearance variation with pressure ratio

$$
\text { Clearance }=-8.684 /\left(\ln \left(P_{R}\right)\right)^{1.5}+34.85
$$

The figure shows that taking $30 \mu \mathrm{m}$ of clearance can be useful for operations between 4 and 5.5 pressure ratios. However, many applications such as solar ORC and waste heat applications, the system operates at off-design conditions. Therefore, taking a constant clearance value causes calculation errors for predicting leakage flow rate.

By using experimentally-obtained clearance data, Fig. 9 has been plotted to compare measured and calculated mass flow rates. Since pressure is increased during the experiment, the system cannot reach steady operation but the difference between calculated and measured value still indicates a satisfactory compatibility. The average deviation is less than $10 \%$.

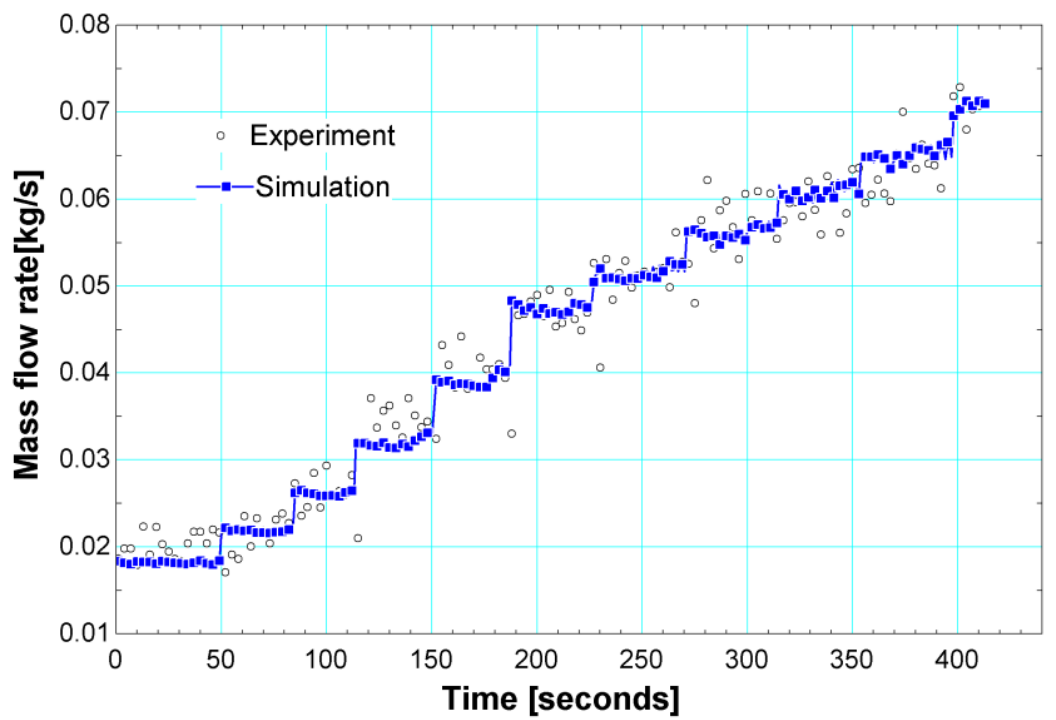

Fig. 9. Measured and calculated flow rates 


\subsection{Volumetric efficiency}

Volumetric efficiency is the ratio of the theoretical flow rate which does not count internal leakage and the actual total flow rate which includes internal leakage inside the expander. The volumetric efficiency is an important parameter as it is one of the indicators of leakages which is also responsible for causing a low performance of the expander. To analyse the volumetric efficiency, Fig. 10 shows the variation of the theoretical and leakage flow rates with the pressure ratio. The theoretical flow rate increases with the inlet pressure as it depends on the inlet density, rotational speed and swept volume of the expander as seen in Eq. (12). Since the expander output pressure is almost constant during this experiment, the pressure ratio increases with inlet pressure, so the theoretical mass flow rate increases with the pressure ratio. However, the trend of theoretical flow rate is more dependent on the variation of rotational speed with the pressure ratio. It is obvious that the rotational speed increases with the pressure ratio. Therefore, the theoretical flow rate has a fairly shaper trend of increase because of the combined effect of increased inlet pressure and rotational speed.

The leakage flow rate also increases with the pressure ratio but with a flatter trend. As seen in Eq. (13), the leakage flow rate is related to the inlet condition, the effective leakage area and also the maximum value between the outlet pressure and the critical throat pressure. The pressure ratios in the experiment is already larger than the critical pressure ratio given by Eq. (14), so the critical pressure is actually used in calculation of leakage flow rate, but it is given by the inlet pressure and ratio of specific heat. Therefore, the trend of leakage flow rate would more depend on the effective leakage area. Referring back to Fig. 8, the clearance between scrolls changes with the pressure ratio, so the effective leakage area changes with pressure ratio according to Eqs. (10)-(11). For this reason, the leakage flow rate would increase faster when the pressure ratio is about 3.5 and then has a smaller increment with the pressure ratio.

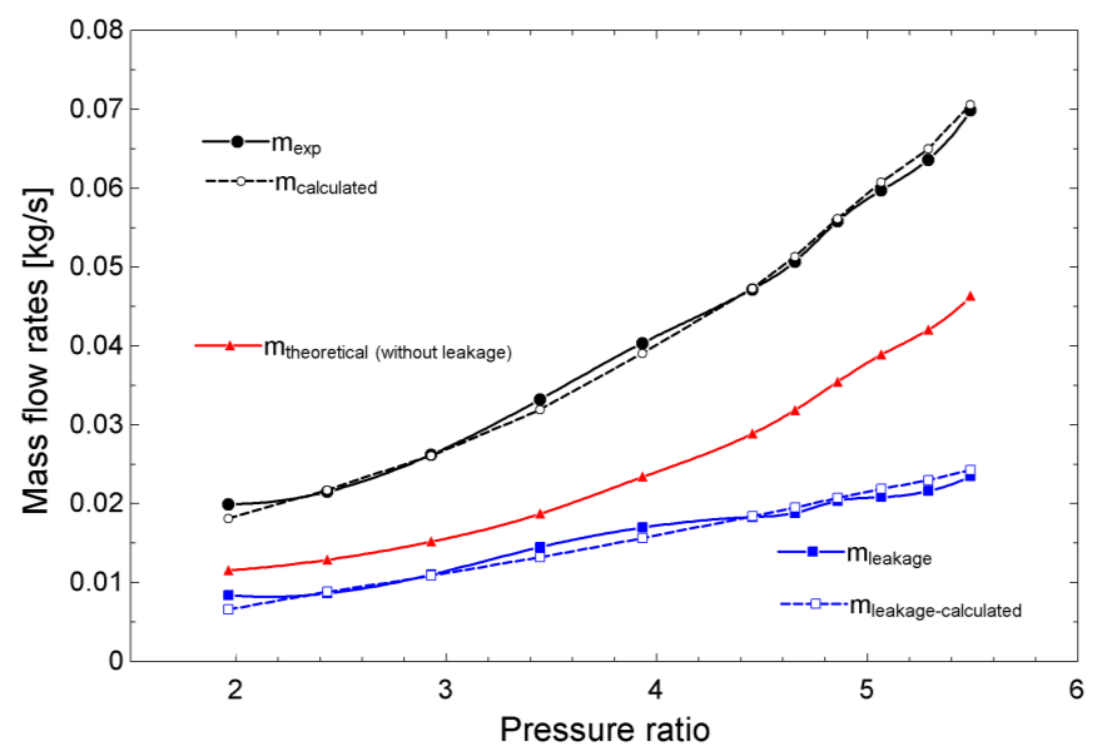

Fig.10. Theoretical, leakage and measured total flow rates and calculated leakage and total flow rates

Based on calculation of the flow rates as shown in Fig.10, Fig. 11 shows the variation of volumetric efficiency with pressure ratio. Usually, the volumetric efficiency is expected to have a simple increasing trend with the pressure ratio because a higher rotational speed 
generally results in a better volumetric efficiency. However, the variation of leakage flow rate with the pressure ratio can have an influence on this trend. Because the theoretical flow rate and leakage flow rate show different trends of increase as shown in Fig. 10, the volumetric efficiency curve shows a valley around the pressure ratio of 3-4.

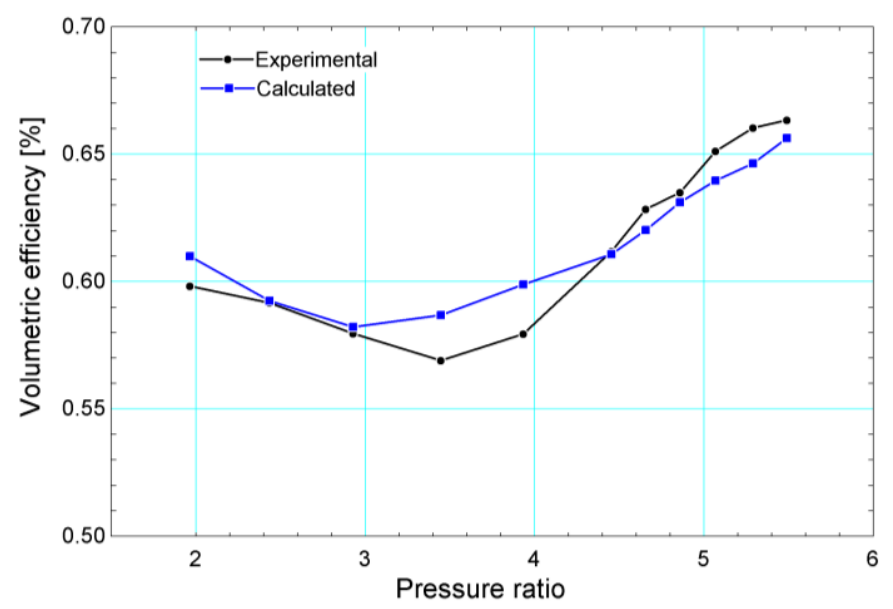

Fig.11. Variation of volumetric efficiency with pressure ratio

\subsection{Prediction of rotational speed and electricity output}

The rotational speed is one of the important parameters as it affects the mass flow rate and electrical current in the coupled expander-generator unit. To determine the rotational speed of the expander, a torque balance should be considered. For the steady state operation, Eq. (26) is deduced as Eq. (31) to eliminate inertia and acceleration effects of the components.

$$
T_{t}-T_{f r}-T_{e m}=0
$$

In order to compare the simulation results with the experiment, forty steady state points have been considered from five sets of conditions. In each set, the evaporator temperature is kept almost constant and supply pressure is increased gradually. Variations of the inlet supply pressure, outlet exhaust pressure and rotational speed recorded in the experiment are given in Fig. 12.
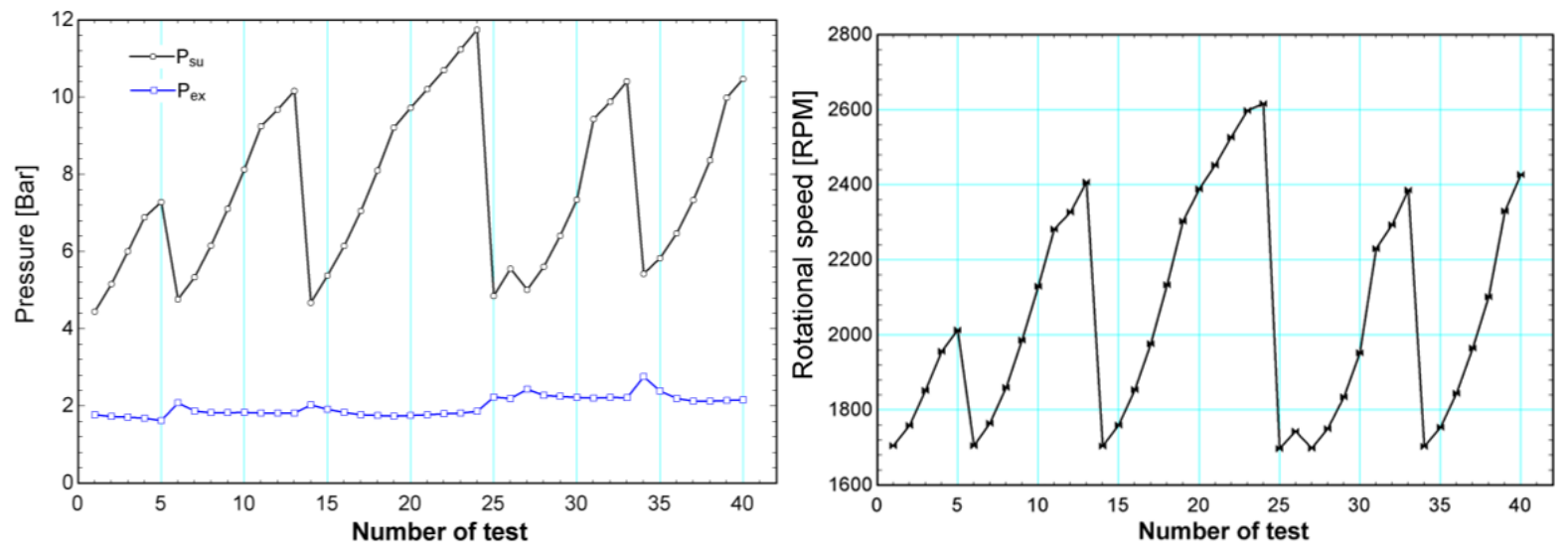

Fig.12. Operating conditions for five sets of tests 
Before analysing the data, the factors affecting the rotational speed are to be clarified. As recommended by $\mathrm{Ma}$ et al. [25], Eq. (28) presents a simple relationship between the electromechanical torque and current. However, in order to make the study more reliable, other literature has been reviewed and hence Eq. (28) has been modified to Eq. (32), which includes a new parameter called as flux per pole [45]:

$$
T_{e m}=K_{e} \Phi_{d} I_{a}
$$

Since the flux depends on the current in the generator, the variation is obtained from the experiment by following the procedure in Fig. 4. Results are given in Fig. 13a. The friction torque is quite complicated to determine, given that the expander has components and frictions occurring between them, and the generator also has friction between its components. An overall dynamic friction coefficient $\left(f_{s g}\right)$ is therefore used to find the friction torque, as given in Eq. (27). $f_{s g}$ can be determined by fitting of experimental data with respect to the rotational speed of the expander, as shown in Fig. 13b.
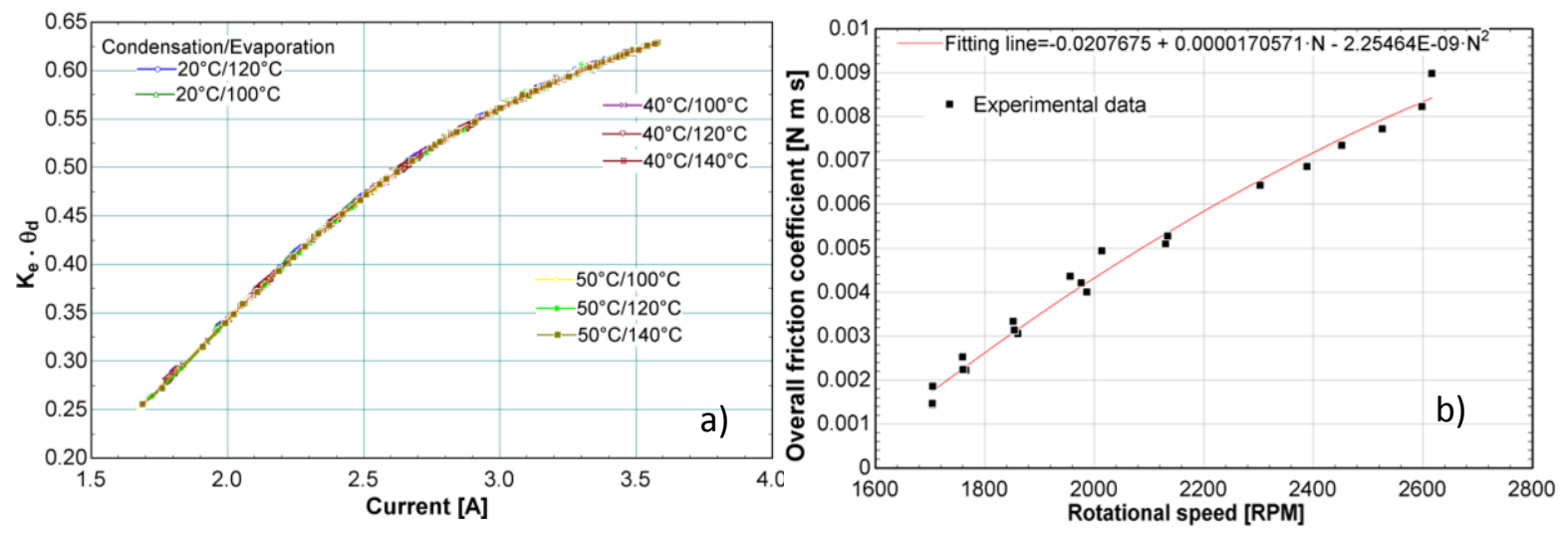

Fig. 13. Experimentally-obtained generator characteristic (a) and overall friction coefficient of the system (b)

After obtaining the empirical equations, simulation for predicting the rotational speed and electricity output can be conducted. In order to compare simulation results with the experimental data, the same operating parameters are selected. Fig. 14 shows the followed flow chart. The procedure is started with assumption of the current and rotational speed. The semi-empirical model uses scroll geometry to calculate expander areas to find heat transfer rates (H.T.) and then shaft power is found. The shaft power is converted into driving torque and voltages are compared, one from the torque balance and the other from the assumed current. Then, the rotational speed is updated, and shaft power is recalculated using a new rotational speed. Error $V$ and Error $I_{a}$ indicate difference between assumed and calculated parameters. This procedure continues until the difference satisfies the condition. The convergence condition for heat balance is used to update the scroll expander shell temperature and we have evaluated that its effect on shaft power is quite limited. By keeping this value lower, the results can be slightly more accurate, but it increases computational time. To show its effect on shaft power output, different convergence conditions have been 
studied from $10 \mathrm{~W}$ to $0.01 \mathrm{~W}$. The results show that the shell temperature reduces from 73.2 ${ }^{\circ} \mathrm{C}$ to $72.51{ }^{\circ} \mathrm{C}$ and the shaft power changes by only $0.1 \mathrm{~W}$. As effect on the shaft power is negligible, $10 \mathrm{~W}$ convergence condition is chosen, and hence the computational time is reduced. Similar analyses have been also done for voltage and current convergence conditions and it is found that the chosen 0.05 Volt and $0.05 \mathrm{~A}$ can ensure a sufficient accuracy in iteration.

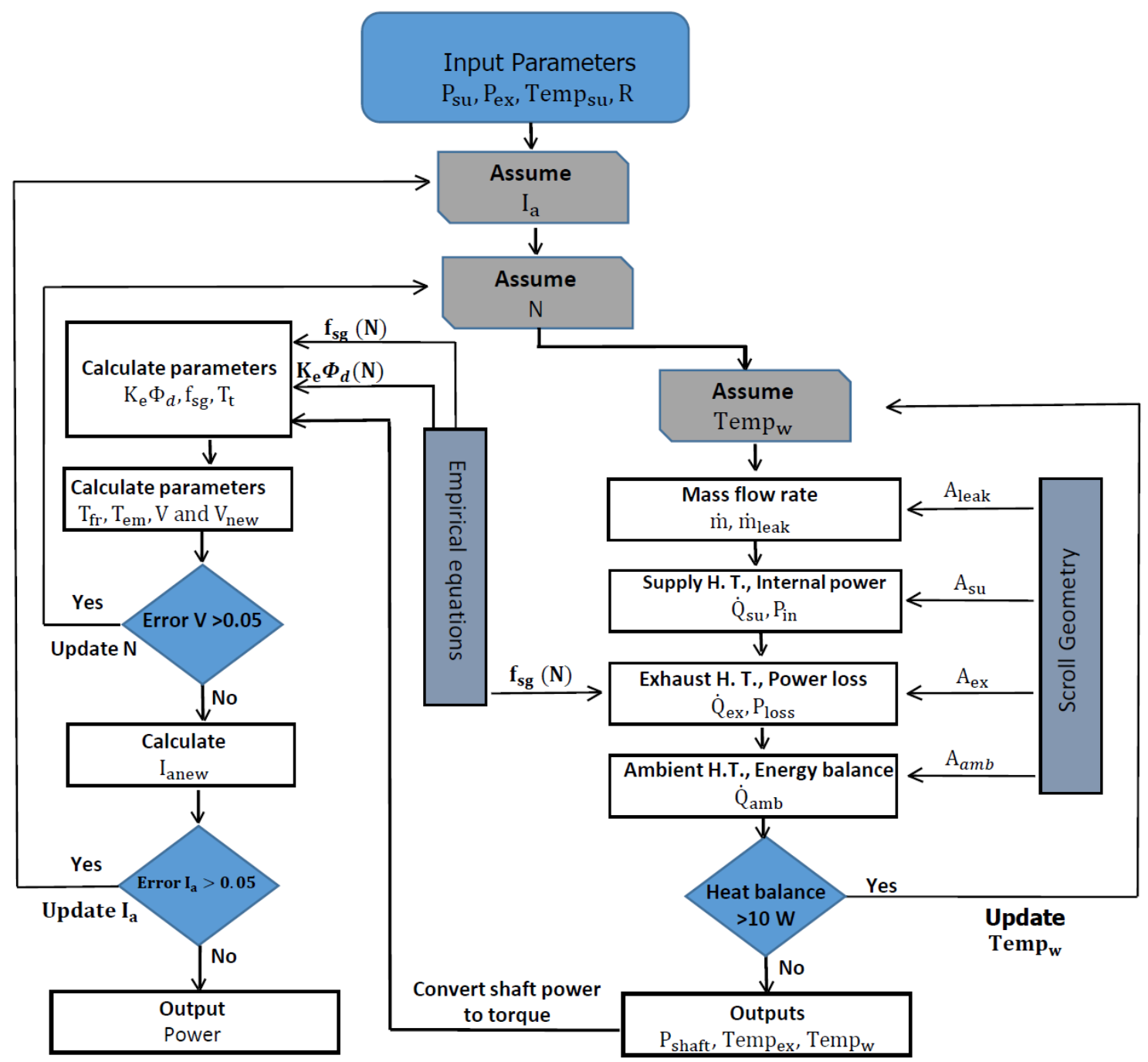

Fig. 14. A procedure for predicting the rotational speed and electricity output

Fig. 15 shows the comparison of the calculated and experimental results of the rotational speed. Deviation is small for low inlet pressure operations but increases with higher inlet pressure. However, rotational speed also increases with pressure, thus, maximum deviation reaches $8 \%$. The deviation can be reduced by decreasing the convergence criteria of conditions, though computational time increases in this case. 


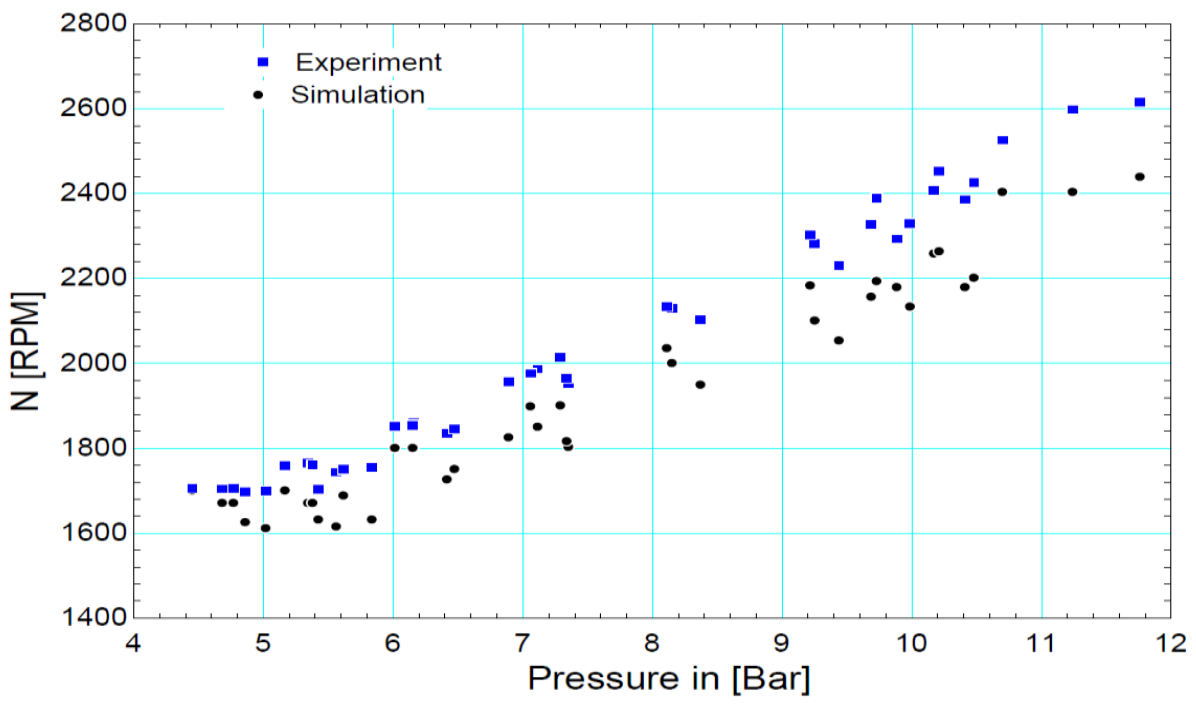

Fig. 15. Comparison between the experimental and simulated results of the rotational speed

Fig. 16 shows a comparison of simulated and experimental results of electricity output. Prediction of electricity output values are in good agreement with the test results, especially under low pressure operations. Accuracy of the model can be improved when high computational execution time is considered; however, the results prove that the given methodology can predict the rotational speed of the expander and electricity output in an acceptable deviation. The proposed methodology reduces the empirical parameters of the semi-empirical approach to only two parameters which are friction loss coefficient and clearance value. Furthermore, the proposed approach can predict rotational speed and generator output. These parameters make this analysis more applicable for system design and performance evaluation for various applications.

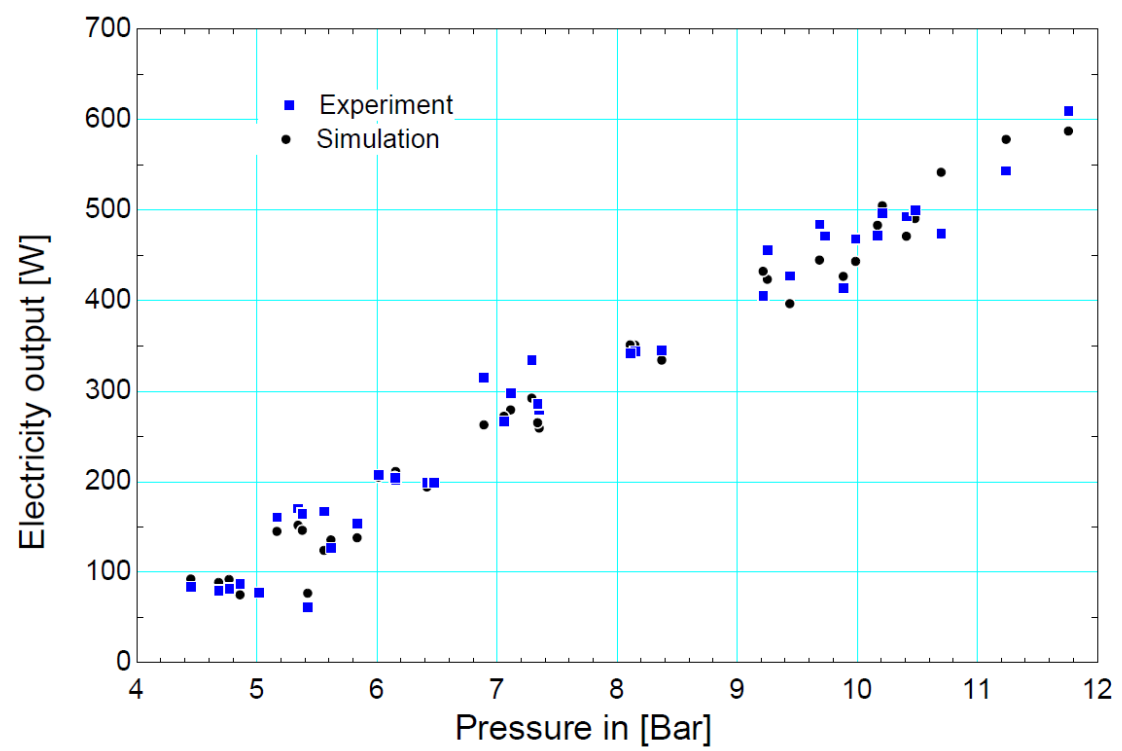

Fig. 16. Comparison between the experimental and simulated results of electricity output 


\section{Conclusions}

In this study, a methodology for modelling of the scroll expander has been given. As a semiempirical approach is used by many researchers, given its simplicity and accuracy under varying operating conditions, the main objective of this study was to improve the semiempirical modelling. Since the most preferred semi-empirical model has several empirically dependent parameters, this study aimed to reduce the number of empirical parameters by using scroll geometry to enhance the flexibility of this approach. Those parameters only related to scroll geometry can be found by using the presented scroll profile equations. A simulation model has been built and validated by experimental results. Particularly, the study has presented a procedure to determine the leakage area and friction torque. Two empirical correlations for the clearance between scrolls and the overall friction coefficient have been determined according to the experimental data. Some important conclusions are drawn as follows:

- The effective leakage area in the semi-empirical modelling can be found using scroll geometry equations and empirical clearance equation. Mass flow rate was predicted with a maximum deviation of $10 \%$ under transient conditions.

- The effective clearance between scrolls change with the pressure ratio. The clearance value starts with around $20 \mu \mathrm{m}$ and increase with pressure. Experimentally-obtained logarithmic function shows that $34 \mu \mathrm{m}$ is the maximum clearance when the pressure ratio becomes really large.

- The overall dynamic friction coefficient of the coupled expander-generator unit has been determined experimentally using a semi-empirical approach. It varied from $0.002 \mathrm{Nms}$ to $0.009 \mathrm{~N} \mathrm{~ms}$ with rotational speed for a $1 \mathrm{~kW}$ scroll expandergenerator unit.

- Heat transfer areas were calculated from scroll geometry while heat transfer coefficients were determined from some empirical heat transfer correlations.

- The model predicted the rotational speed of the coupled expander-generator unit with less than $8 \%$ deviation and electricity output with an average $7.5 \%$ deviation.

\section{ACKNOWLEDGEMENTS}

The authors would like to thank the European Commission for the Marie Curie Fellowship grant (H2020-MSCA-IF-2014-658217, H2020-MSCA-IF-2015-703746).

\section{Nomenclature}

\begin{tabular}{clcc}
$A$ & Area, $\mathrm{m}^{2}$ & \multicolumn{2}{c}{ Subscripts } \\
$A U$ & Heat transfer coefficient-heat transferring & a & Armature \\
& area, $\mathrm{W} \mathrm{K}^{-1}$ & & \\
BVR & Built-in volumetric ratio, - & ad & Adapted
\end{tabular}


$h_{s} \quad$ Scroll height, $\mathrm{m}$

$I_{a} \quad$ Current, A

$\mathrm{J} \quad$ Moment of inertia, $\mathrm{kg} \mathrm{m}^{2}$

$K_{e} \quad$ Constant of back electromotive force, $\mathrm{V} \mathrm{s} \mathrm{rad}{ }^{-1}$

$K_{t} \quad$ Torque constant, $\mathrm{N} \mathrm{m} \mathrm{A}^{-1}$

$L \quad$ Tangential distance, $\mathrm{m}$

$L_{a} \quad$ Armature inductance, $\mathrm{H}$

$\dot{m} \quad$ Mass flow rate, $\mathrm{kg} \mathrm{s}^{-1}$

$\mathrm{N} \quad$ Rotational speed, RPM

$N_{c} \quad$ Number of chambers, -

$\mathrm{Nu} \quad$ Nusselt number, -

$\mathrm{P} \quad$ Pressure, $\mathrm{Pa}$

Pit Scroll pitch, $m$

Pr Prandtl number, -

$R \quad$ Resistance, $\Omega$

Re Reynolds number, -

$\dot{Q} \quad$ Heat transfer rate, $\mathrm{W}$

$r_{b} \quad$ Basic circle radius, $\mathrm{m}$

St Strouhal number, -

$\mathrm{T} \quad$ Torque, $\mathrm{N} \mathrm{m}$

Temp Temperature, ${ }^{\circ} \mathrm{C}$

$t$ thickness, $m$

$\bar{U} \quad$ Mean flow velocity, $\mathrm{m} \mathrm{s}^{-1}$

$V \quad$ Volume, $\mathrm{m}^{3}$

$\dot{W} \quad$ Power, $\mathrm{W}$

\section{Greek letters}

$\gamma \quad$ Isentropic exponent, -

$\delta \quad$ leakage clearance size, $\mathrm{m}$

$\theta \quad$ orbiting angle, rad

$\rho \quad$ Density, $\mathrm{kg} \mathrm{m}^{-3}$

$\phi \quad$ Involute angle, rad

$\omega \quad$ Angular velocity, $\mathrm{rad} \mathrm{s}^{-1}$

amb Ambient

b Base

c Chamber

crit Critical

DB Dittus Boelter

dis Discharge

e End

em Electromechanical

ex Exhaust

f Flank

fr Friction

i Inner

i0 Inner initial

(i) Number of chambers

h hydraulic

leak Leakage

m Mean

n Nominal

o Outer

o0 Outer initial

old Oldham

or Orbiting

$\mathrm{p}$ plate

r Radial

s scroll

sh Shell

sha

su Supply

suc Suction

sw Swept

$\mathrm{t}$ Tangential

w Wall (expander shell)

0 initial

\section{References}

[1] Quoilin S, Lemort V, Lebrun J. Experimental study and modeling of an Organic Rankine Cycle using scroll expander. Appl Energy 2010;87:1260-8. https://doi.org/10.1016/j.apenergy.2009.06.026.

[2] Dickes R, Dumont O, Daccord R, Quoilin S, Lemort V. Modelling of organic Rankine cycle power systems in off-design conditions : An experimentally-validated comparative study. Energy 2017;123:710-27. https://doi.org/10.1016/j.energy.2017.01.130.

[3] Saitoh T, Yamada N, Wakashima S. Solar Rankine Cycle System Using Scroll Expander. J Environ Eng 2007;2:708-19. https://doi.org/10.1299/jee.2.708. 
[4] Garcia-saez I, Mendez J, Ortiz C, Loncar D, Becerra JA, Chacartegui R. Energy and economic assessment of solar Organic Rankine Cycle for combined heat and power generation in residential applications. Renew Energy 2019;140:461-76. https://doi.org/10.1016/j.renene.2019.03.033.

[5] Kutlu C, Tahir M, Li J, Wang Y, Su Y. A study on heat storage sizing and fl ow control for a domestic scale solar-powered organic Rankine cycle-vapour compression refrigeration system. Renew Energy 2019;143:301-12.

https://doi.org/10.1016/j.renene.2019.05.017.

[6] Song P, Wei M, Shi L, Danish SN, Ma C. A review of scroll expanders for organic rankine cycle systems. Appl Therm Eng 2015;75:54-64.

https://doi.org/10.1016/j.applthermaleng.2014.05.094.

[7] Lemort V, Quoilin S, Cuevas C, Lebrun J. Testing and modeling a scroll expander integrated into an Organic Rankine Cycle. Appl Therm Eng 2009;29:3094-102. https://doi.org/10.1016/j.applthermaleng.2009.04.013.

[8] Dumont O, Dickes R, Lemort V. Extrapolability and limitations of a semi-empirical model for the simulation of volumetric expanders. Energy Procedia 2017;129:315-22. https://doi.org/10.1016/j.egypro.2017.09.198.

[9] Ziviani D, Gusev S, Lecompte S, Groll EA, Braun JE, Horton WT, et al. Characterizing the performance of a single-screw expander in a small-scale organic Rankine cycle for waste heat recovery. Appl Energy 2016;181:155-70. https://doi.org/10.1016/j.apenergy.2016.08.048.

[10] Giuffrida A. Improving the semi-empirical modelling of a single-screw expander for small organic Rankine cycles. Appl Energy 2017;193:356-68.

https://doi.org/10.1016/j.apenergy.2017.02.015.

[11] Bianchi M, Branchini L, Pascale A De, Melino F, Ottaviano S, Peretto A, et al. Application and comparison of semi-empirical models for performance prediction of a kW-size reciprocating piston expander. Appl Energy 2019;249:143-56. https://doi.org/10.1016/j.apenergy.2019.04.070.

[12] Dumont O, Parthoens A, Dickes R, Lemort V. Experimental investigation and optimal performance assessment of four volumetric expanders ( scroll, screw, piston and roots ) tested in a small-scale organic Rankine cycle system. Energy 2018;165:1119-27. https://doi.org/10.1016/j.energy.2018.06.182.

[13] Giuffrida A. Modelling the performance of a scroll expander for small organic Rankine cycles when changing the working fluid. Appl Therm Eng 2014;70:1040-9. https://doi.org/10.1016/j.applthermaleng.2014.06.004.

[14] Lemort V, Declaye S, Quoilin S. Experimental characterization of a hermetic scroll expander for use in a micro-scale Rankine cycle. Proc Inst Mech Eng Part A J Power Energy 2012;226:126-36. https://doi.org/10.1177/0957650911413840.

[15] Mendoza L, Esbri J, Bruno JC, Lemort V, Coronas A. Characterization and modeling of a scroll expander with air and ammonia as working fluid. Appl Therm Eng 2014;70:630-40. https://doi.org/10.1016/j.applthermaleng.2014.05.069.

[16] Giuffrida A. A theoretical study on the performance of a scroll expander in an organic Rankine cycle with hydrofluoroolefins ( HFOs ) in place of R245fa. Energy 
2018;161:1172-80. https://doi.org/10.1016/j.energy.2018.07.146.

[17] Ziviani D, James NA, Accorsi FA, Braun JE, Groll EA. Experimental and numerical analyses of a $5 \mathrm{kWe}$ oil-free open-drive scroll expander for small-scale organic Rankine cycle ( ORC ) applications. Appl Energy 2018;230:1140-56. https://doi.org/10.1016/j.apenergy.2018.09.025.

[18] Gao P, Jiang L, Wang LW, Wang RZ, Song FP. Simulation and experiments on an ORC system with different scroll expanders based on energy and exergy analysis. Appl Therm Eng 2015;75:880-8. https://doi.org/10.1016/j.applthermaleng.2014.10.044.

[19] Twomey B, Jacobs PA, Gurgenci H. Dynamic performance estimation of small-scale solar cogeneration with an organic Rankine cycle using a scroll expander. Appl Therm Eng 2013;51:1307-16. https://doi.org/10.1016/j.applthermaleng.2012.06.054.

[20] Ayachi F, Ksayer EB, Neveu P, Zoughaib A. Experimental investigation and modeling of a hermetic scroll expander. Appl Energy 2016;181:256-67. https://doi.org/10.1016/j.apenergy.2016.08.030.

[21] Miao Z, Xu J, Zhang K. Experimental and modeling investigation of an organic Rankine cycle system based on the scroll expander. Energy 2017;134:35-49. https://doi.org/10.1016/j.energy.2017.06.001.

[22] Muye J, Kumar GP, Bruno JC, Saravanan R, Coronas A. Modelling of scroll expander for di ff erent working fl uids for low capacity power generation. Appl Therm Eng 2019;159. https://doi.org/10.1016/j.applthermaleng.2019.113932.

[23] Emhardt S, Tian G, Chew J. A review of scroll expander geometries and their performance. Appl Therm Eng 2018;141:1020-34.

[24] Bell I. Theoretical and Experimental Analysis of Liquid Flooded Compression in Scroll Compressors, PhD Thesis. Purdue University, 2011.

[25] Ma Z, Bao H, Roskilly AP. Dynamic modelling and experimental validation of scroll expander for small scale power generation system. Appl Energy 2017;186:262-81. https://doi.org/10.1016/j.apenergy.2016.08.025.

[26] Bell IH, Lemort V, Groll EA, Braun JE, King GB, Horton WT. Liquid-flooded compression and expansion in scroll machines - Part I: Model development. Int J Refrig 2012;35:1878-89. https://doi.org/10.1016/j.ijrefrig.2012.07.010.

[27] Chen Y, Halm NP, Groll E a., Braun JE. Mathematical modeling of scroll compressors-part I: compression process modeling. Int J Refrig 2002;25:731-50. https://doi.org/10.1016/S0140-7007(01)00071-8.

[28] Wu Z, Pan D, Gao N, Zhu T, Xie F. Experimental testing and numerical simulation of scroll expander in a small scale organic Rankine cycle system. Appl Therm Eng 2015;87:529-37. https://doi.org/10.1016/j.applthermaleng.2015.05.040.

[29] Liu Y, Hung C, Chang Y. Design optimization of scroll compressor applied for frictional losses evaluation. Int J Refrig 2010;33:615-24. https://doi.org/10.1016/j.ijrefrig.2009.12.015.

[30] Kim D, Chung HJ, Jeon Y, Jang DS, Kim Y. Optimization of the injection-port geometries of a vapor injection scroll compressor based on SCOP under various 
climatic conditions. Energy 2017;135:442-54. https://doi.org/10.1016/j.energy.2017.06.153.

[31] Zhang X, Xu Y, Xu J, Sheng Y, Zuo Z, Liu J, et al. Study on the performance and optimization of a scroll expander driven by compressed air. Appl Energy 2017;186:347-58. https://doi.org/10.1016/j.apenergy.2016.06.004.

[32] Guangbin L, Yuanyang Z, Liansheng L, Pengcheng S. Simulation and experiment research on wide ranging working process of scroll expander driven by compressed air. Appl Therm Eng 2010;30:2073-9. https://doi.org/10.1016/j.applthermaleng.2010.05.015.

[33] Guangbin L, Yuanyang Z, Yunxia L, Liansheng L. Simulation of the dynamic processes in a scroll expander-generator used for small-scale organic Rankine cycle system. Proc Inst Mech Eng Part A J Power Energy 2011;225:141-9. https://doi.org/10.1177/09576509JPE1036.

[34] Xiaojun G, Liansheng L, Yuanyang Z, Pengcheng S, Jiang S. Research on a scroll expander used for recovering work in a fuel cell. Int J Thermodyn 2004;7:1-8. https://doi.org/10.5541/IJOT.1034000120.

[35] Wang J, Luo X, Yang L, Shpanin LM, Jia N, Mangan S, et al. Mathematical modeling study of scroll air motors and energy efficiency analysis - part II. Mechatronics, IEEE/ASME Trans 2011;16:122-32. https://doi.org/10.1109/TMECH.2009.2036607.

[36] Winandy E, O CS, Lebrun J. Experimental analysis and simplified modelling of a hermetic scroll refrigeration compressor. Appl Therm Eng 2002;22:107-20.

[37] Jang K, Jeong S. Experimental investigation on convective heat transfer mechanism in a scroll compressor. Int J Refrig 2006;29:744-53. https://doi.org/10.1016/j.ijrefrig.2005.12.002.

[38] Ishii N, Fukushima M, Sawai K, Sana K, Imaichi K. Dynamic Behavior of a Scroll Compressor. JSME Int J 1988;31:58-67.

[39] Kenjo T, Nagamori S. Permanent-magnet and brushless DC motors. Oxford: Claderon Press; 1985.

[40] Li J, Gao G, Li P, Pei G, Huang H, Su Y. Experimental study of organic Rankine cycle in the presence of non- condensable gases. Energy 2018;142:739-53. https://doi.org/10.1016/j.energy.2017.10.054.

[41] Airsquared n.d. https://airsquared.com/products/scroll-expanders/e15h022a-sh/ (accessed November 25, 2019).

[42] Holman JP. Experimental Methods for Engineers. Seventh ed. McGraw-Hill Series in Mechanical Engineering; 2001.

[43] Vernier Caliper n.d. https://www.physics.smu.edu/ scalise/apparatus/caliper/ (accessed April 6, 2020).

[44] Calipers guide n.d. https://uk.rs-online.com/web/generalDisplay.html?id=ideas-andadvice/calipers-guide (accessed April 8, 2020).

[45] Fitzgerald AE, Kingsley C, Umans S. Electric Machinery. 6th Editio. McGraw-Hill; 2002. 